\title{
Factors Associated with Agreeing to Early Childbearing Among School Girls of Selected Rural Districts in Zambia
}

\author{
Priscilla Nkonde ${ }^{1}$, Cheelo Mweene ${ }^{1}$, Patrick Musonda ${ }^{1,2}$ \\ ${ }^{1}$ School of Public Health, Department of Epidemiology and Biostatistics, University of Zambia, Lusaka, Zambia \\ ${ }^{2}$ Centre for Intervention Science in Maternal and Child health (CISMAC), Centre for International Health (CIH), University of Bergen, \\ Bergen, Norway
}

\section{Email address:}

Priscillankonde@yahoo.com(P. Nkonde),Cheelo.mweene.cheelo@gmail.com(C.Mweene),pmuzho@hotmail.com(P.Musonda)

\section{To cite this article:}

Priscilla Nkonde, Cheelo Mweene, Patrick Musonda. Factors Associated with Agreeing to Early Childbearing Among School Girls of Selected Rural Districts in Zambia. International Journal of HIV/AIDS Prevention, Education and Behavioural Science.

Vol. 5, No. 1, 2019, pp. 52-58. doi: 10.11648/j.ijhpebs.20190501.17

Received: March 12, 2019; Accepted: April 17, 2019; Published: May 20, 2019

\begin{abstract}
Background: The Zambia Demographic Health survey conducted in 2014 reported a notable number of adolescent girls 3627(11.7\%) who had their first sexual intercourse by age 15 and the Zambia National Health Strategic Plan 2017-2021 highlighted the high adolescent birth rate which stood at 141 per 1000 live births between the years 2013 and 2014 . In this paper, we adopted the WHO definition of an Adolescent as any person between the ages of 10 to 19 years. This study aimed at investigating baseline factors that leads to agreeing into early childbearing practices among adolescent girls in selected rural districts of Zambia nested in the RISE cluster randomized trial. In this study early childbearing was taken to mean any pregnancy before the age of 16. Methods: This study is a nested quantitative cross-sectional design. Participants were girls attending grade seven at various schools in 2016. Information on factors that could influence the participants' view on childbearing were collected at baseline. A complete enumeration of approximately 5000 girls recruited in 12 rural districts of Central and Southern provinces were analysed. Descriptive statistics were presented as frequencies and percentages in tables. To check for association with categorical variables, either Chi-squared or Fisher's exact test was done depending on whether the assumptions for Chi-squared test were satisfied or not. Univariate and Multiple Logistic regression analysis was used to test the association between independent factors and early childbearing. Clustering in the study was accounted for using robust standard errors. Results: The findings showed that more than two-thirds $3189(73.7 \%)$ of the participants had little or no knowledge regarding adolescent sexual and reproductive health services while less than one-third 1137 (26\%) had knowledge regarding Adolescent Sexual and Reproductive Health services. Adolescents with mobile phones were 2.5 times more likely to have children early compared to adolescents without mobile phones. Majority 227 (69\%) who agreed to early childbearing were aged 10 to 15 years, whilst the least 99(30.3\%) were in the age range of 16 to 20 years. In addition, results revealed that one-year increase in age of an adolescent girl increases agreeing to early childbearing by $30 \%(\mathrm{OR}=1.30,95 \% \mathrm{CI}(1.01,1.67)$, $\mathrm{p}$ - value $=0.03$ ). Overall, very few factors (mobile phone and age) at baseline were found to be associated with agreeing to early childbearing. Conclusions: Only mobile phone use and age were associated with agreeing to early childbearing.
\end{abstract}

Keywords: Early Childbearing, Knowledge, Adolescent, Reproductive Health

\section{Introduction}

Adolescent early childbearing has not only become a public health issue, but also a media focal point because of its societal, socio-economic and health impact. Early childbearing is a complex and serious problem in the world today and it has many negative implications on society, economy, and youth. Early childbearing is a major health concern because of its association with higher morbidity and mortality for both the mother and child. Childbearing during the adolescent years also has adverse social consequences, particularly on female education attainment, because women who become mothers in their early years are more likely to curtail education [1]. 


\subsection{The Rise Trial}

This study was nested in the Research Initiative to Support the Empowerment (RISE) of Girls trial. The RISE trial is aimed at measuring the effect of cash transfers on early childbearing, school drop outs and early marriage rates in a rural Zambian context. RISE is trying to do this by using an intervention of economic support to girls and their families, and secondly a combination of the economic support with a community intervention to enhance knowledge about sexual and reproductive health and supportive community norms. RISE is a cluster randomized controlled trial (CRCT) with three arms. The clusters are rural schools with surrounding communities and approximately 5000 girls who were in grade 7 in 2016 were recruited from 157 schools in 12 rural districts. The study is on-going until 2020 [2].

Adolescent childbearing rates vary between regions and countries, and often variation can occur within the same country. Teenage pregnancies are less in developed countries and are more than twice as high compared to rates in developing countries. In the least developed countries, the rate is almost five times as the rate in the more developed countries. The variations are also striking at the country level. The percentage of girls 15-19 giving birth ranges from less than $1 \%$ per year in places like Japan and Korea, to over $20 \%$ per year in the Democratic Republic of Congo [3].

In addition, nearly 16 million women aged between 15-19 years give birth each year, which accounts for $11 \%$ of all births worldwide. In low and middle income countries, almost $10 \%$ of girls become mothers by the age 16 , with the vast majority being in sub-Saharan Africa [4]. The proportion of women who become pregnant before age 15 varies enormously even within regions and countries. For example, the rate in Rwanda is $0.3 \%$ compared to $12.2 \%$ in
Mozambique [5].

Early childbearing has become a very serious social problem in Zambia and rural areas in particular, and pregnancy under the age of seventeen has been viewed as a catastrophe for most individuals, family and the district as a whole [6]. Nowadays it appears like teenage mothers are having more babies compared with a generation ago. Moreover, the younger adolescents are when having their first child, the more likely they are to have another child whilst teenagers.

The society in which adolescents grow up has an important influence on their development, relationships, adjustments and problems. Adolescents from rural areas live in a society that is characterised by poverty with almost the whole population being seasonal peasant farmers. Seasonal peasant farming cannot curb the problem of unemployment in the rural areas, as a result, most adolescents do not go to school because their parents cannot afford to sponsor their education. Additionally, most people in rural areas lack basic needs and adolescents tend to look for other alternatives as a means of survival by engaging themselves in promiscuous activities hence early childbearing [7].

Although the legal age at which a girl can consent to sex is 16 years old in the Zambian civil law, the legal age of marriage is 21 years. However, under customary law, (which represents the 'traditional system in Zambia') the girl can get married as soon as she reaches puberty [8].

In Zambia, as any other part of Africa, a couple is expected to start childbearing soon after marriage. Thus, early marriage automatically indicates early childbearing, possibly short birth intervals and many births. The woman therefore risks impairing her health as a result of early or frequent births due to early childbearing.

\subsection{Conceptual Framework Examining Factors Associated with Agreeing to Early Childbearing Among Adolescent Girls}

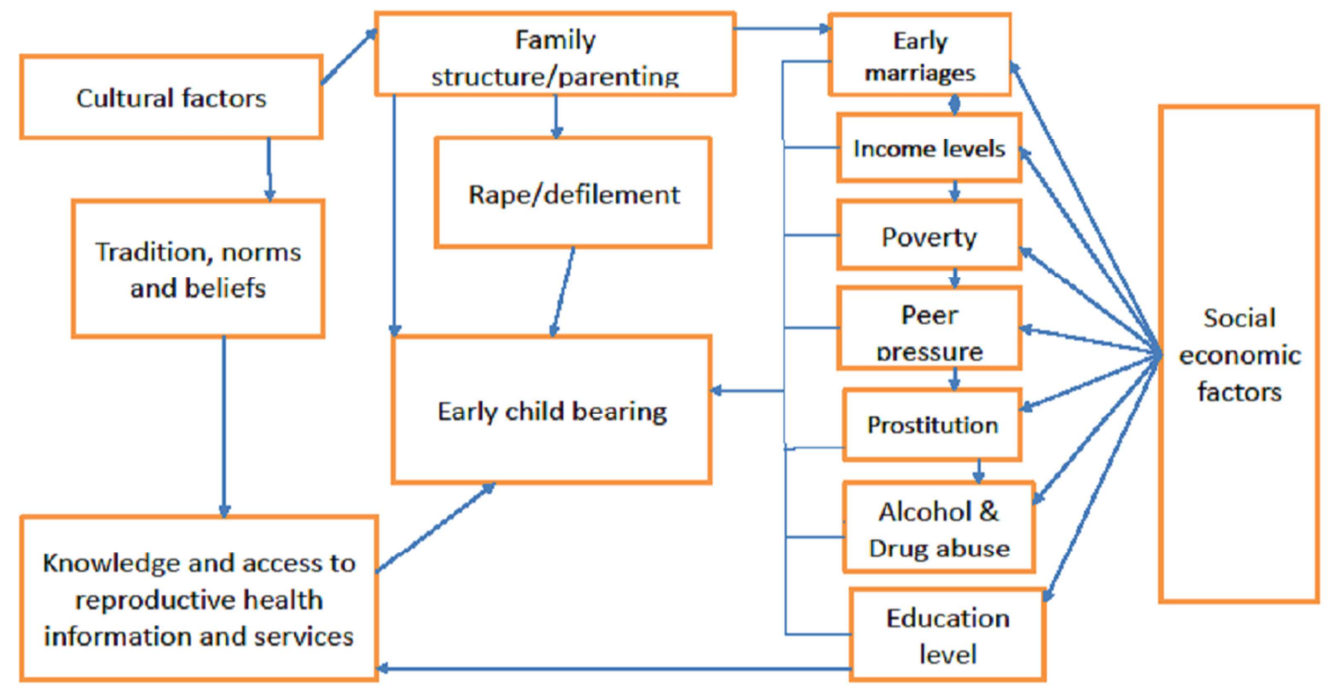

Figure 1. Theoretical framework adopted from Gibbons et al 1998.

The conceptual framework used in this study was adopted from the Prototype/Willingness theory that is designed specifically to apply to unplanned behaviours, such as adolescent sex [9]. The framework revealed that most of the 
identified social and economic factors cause each other. It can be deduced that an adolescent who lives in poverty is more likely to engage herself in prostitution due to low levels of income at home and peer pressure. In addition, most poor parents do not have enough income to provide basic needs to their female children; as a result they decide to marry them off at a tender age thereby exposing them to early childbearing. Most of the decisions that adolescents make are peer oriented. Therefore, alcohol and drug abuse are mostly catalysed by peer pressure hence early childbearing. Furthermore, when someone has high levels of education, they are capable of visiting reproductive health service providers for knowledge on contraceptives and vice-versa henceforth both education level and knowledge and access to reproductive health services contribute to early childbearing. Cultural factors such as beliefs, norms, values and tradition in the sense that in some traditions early childbearing is promoted and other traditions do not allow the use of contraceptives and this has an effect on early childbearing and teenage pregnancy.

\section{Methods and Materials}

What are the determinants of agreeing to early childbearing among adolescent girls in selected rural districts of Zambia? This study identified some individual socio and economic factors (mobile phone use) and knowledge gaps on reproductive health information (family planning use by adolescent girls) contributing to agreeing into early childbearing practices among adolescent girls of selected rural districts. The findings of this study will help researchers advance their understanding on the relationship between different social and economic factors and how they influence an adolescent girl to agree into early childbearing. It will further add to the existing knowledge about early childbearing studies among adolescent girls in rural areas. Deep understanding of this problem following results of this study will help lay a stepping stone for further in depth studies towards understanding this social phenomenon and how to curb it.

The information will further be used for effective planning and designing of interventions for minimising the problem and the negative impacts it has on adolescents. The study has produced vital information for decision makers, donors and other relevant stake holders that are involved and intend to be involved into early childbearing prevention or reduction programs.

This study was nested in the cluster randomised trial entitled "Research Initiative to Support the Empowerment (RISE) of Girls trial" [8]. The study took place in 12 districts of rural Zambia, namely: Kalomo, Choma, Pemba, Monze, Mazabuka, Chikankata, Chisamba, Chibombo, Kabwe Rural, Kapiri Mposhi, Mkushi and Luano. Study participants were girls in grade seven recruited in 157 schools.

For this study, baseline information that was collected by the "Research Initiative to Support the Empowerment of girls" (RISE) clinical trial was analysed in a cross section sense. The study analysed data of approximately 4900 girls recruited at baseline.

\subsection{Study Variables}

The response (outcome) variable for this study was a proxy to early childbearing which was a categorical variable with respect to responding yes or not to the question of either one was agreeing or disagreeing to having a child early. The explanatory variables for this study includes; knowledge, cultural norms, attitude and socio-economic factors.

\subsection{Statistical Methods}

Complete enumerations of approximately 5000 girls recruited in the RISE trial were analysed. We only used responses at baseline from the study districts in Central and Southern provinces. Descriptive statistics are presented as frequencies and percentages for categorical variables.

Binary logistic regression was used to check for association with categorical variables, for frequencies that were above five and met the assumption of Chi-squared test they were tested using Chi-squared test and all frequencies that were below five were tested using Fisher's exact test. In order to rule out chance finding multiple logistic regression was done in which variables were fitted in the model following the formula: $\operatorname{logit}(\mathrm{y})=\mathrm{a}+\beta 1 \chi 1 \ldots+\beta 1 \chi 2$. In which all the independent variables were fitted in a model and checked for their association with the outcome variable "agreeing to early childbearing" using odds ratios and $\mathrm{P}$ values as a guide. Insignificant variables were removed in the model one by one starting with the highest $\mathrm{p}$ values using backward stepwise logistic regression until the model remained with only significant variables. Clustering in this study was accounted for using robust standard errors because there was no data weighting in the RISE trial.

\section{Results}

Table 1 shows the total number of adolescent girls agreeing to early childbearing $326(6.4 \%)$ and total number of adolescents disagreeing to early childbearing was 4735 (93.5\%). The age distribution ranged from 10 to 19 years as shown above. Most respondents agreeing to early childbearing $227(69.6 \%)$ were aged 10 to 15 years, the least agreeing to early childbearing $99(30.3 \%)$ were in the age group of 16 to 20 years. The majority of the respondents who agreed to early childbearing 218 (62.8\%) were from southern province, the least 129 (37.1\%) were from central province.

According to Zambia Central Statistics Office, the minimum acceptable number of household members per household is five [6]. In this study, the majority 2943 $(62.1 \%)$ of adolescent girls responded to having more than five household members in their house being below the age of 18 and these adolescent girls agreed to early childbearing. A small number of adolescent girls who agreed to early childbearing 1796(37.8) was from a household with less than 5 household members below the age of 18 years. 
More adolescent girls who had their biological fathers alive agreed to early childbearing $263(82.7 \%)$, while a fewer number was from adolescent girls with no biological father alive 55(17.2\%).

Table 1. Social demographic characteristics - univariate comparison.

\begin{tabular}{|c|c|c|c|}
\hline \multirow[t]{2}{*}{ Characteristics } & Agreeing to early childbearing $n=326(6.4 \%)$ & $\begin{array}{l}\text { Disagreeing to early childbearing } n=4735 \\
(93.5 \%)\end{array}$ & \multirow[t]{2}{*}{ P value } \\
\hline & Frequency (\%) & Frequency (\%) & \\
\hline \multicolumn{4}{|l|}{ Age Group } \\
\hline $10-15$ & $227(69.6 \%)$ & $3525(74.54 \%)$ & \multirow[t]{2}{*}{$0.055^{\mathrm{a}}$} \\
\hline $16-20$ & $99(30.3 \%)$ & $12(0.25 \%)$ & \\
\hline \multicolumn{4}{|l|}{ Province } \\
\hline Central & $129(37.1 \%)$ & $1909(40.2 \%)$ & $0.254^{\mathrm{a}}$ \\
\hline \multicolumn{4}{|l|}{ Household member greater than 18 years } \\
\hline Number $\leq 5$ persons per household & $245(74.4 \%)$ & $3575(75.4 \%)$ & \multirow[t]{2}{*}{$0.908^{\mathrm{b}}$} \\
\hline Number $>5$ persons per household & $81(24.6 \%)$ & $1164(24.5 \%)$ & \\
\hline \multicolumn{4}{|l|}{ Household member less than 18 years } \\
\hline Number $\leq 5$ persons per household & $1796(37.8 \%)$ & $108(33.1 \%)$ & \multirow[t]{2}{*}{$0.085^{\mathrm{b}}$} \\
\hline Number $>5$ persons per household & $218(66.87 \%)$ & $2943(62.1 \%)$ & \\
\hline \multicolumn{4}{|l|}{ Biological father alive } \\
\hline No & $55(17.2 \%)$ & $722(15.5 \%)$ & $0.411^{\mathrm{a}}$ \\
\hline \multicolumn{4}{|l|}{ Biological mother alive } \\
\hline No & $21(6.6 \%)$ & $299(6.4 \%)$ & \multirow[t]{2}{*}{$0.903^{\mathrm{a}}$} \\
\hline Yes & $297(93.3 \%)$ & $4351(93.5 \%)$ & \\
\hline
\end{tabular}

KEY: ${ }^{\mathrm{a}}=$ Chi-squared P-value, ${ }^{\mathrm{b}}=$ fishers exact P-value.

Table 2 shows results for Unadjusted and Adjusted Variables Investigating Association with agreeing to Early Childbearing among Adolescent Girls of Selected Rural Districts of Zambia.

Logistic regression analysis was done in which odds ratios of agreeing to early child bearing and 95\% confidence intervals with p-value set at 5\% level of significance are reported in this paper. The study shows that age $(\mathrm{OR}=1.30$, $95 \%$ CI $\{1.01,1.67\} \mathrm{p}$-value $=0.039)$ and mobile phone
$(\mathrm{OR}=2.05$, p- value $=0.003,95 \%$ CI $\{1.26,3.32\})$ were associated with early childbearing at baseline in the RISE trial. In addition, with regards to knowledge in adolescent sexual and reproductive health, despite the insignificant result ( $p$-value $(0.200), \mathrm{OR}=1.18,95 \% \mathrm{CI}\{0.91,1.53\}$ ), 3404 girls (74\%) had no knowledge regarding adolescent sexual reproductive health while 1226 girls (26\%) had knowledge.

Table 2. Unadjusted and adjusted variables investigated for the association with early childbearing among adolescent girls of selected rural districts of Zambia.

\begin{tabular}{|c|c|c|c|c|}
\hline Early childbearing & COR ( 95\% Confidence Interval) & P value & AOR (using robust standard error) ( $95 \%$ Confidence Interval) & Pvalue \\
\hline Knowledgeable & Ref & & & \\
\hline Not Knowledgeable & $1.16(0.89,1.49)$ & 0.253 & $1.18(0.91,1.53)$ & 0.200 \\
\hline Not Cultural & Ref & & & \\
\hline Cultural & $0.877(0.65,117)$ & 0.385 & $0.89(0.65,1.21)$ & 0.456 \\
\hline \multicolumn{5}{|l|}{ Age Group } \\
\hline 10 To 15 & Ref & & & \\
\hline 16 To 20 & $1.27(0.99,1.62)$ & 0.055 & $1.30(1.01,1.67)$ & 0.039 \\
\hline Lowest Class & Ref & & & \\
\hline Second Class & $0.85(0.63,1.14)$ & 0.325 & $0.86(0.64,1.16)$ & 0.329 \\
\hline Middle Class & $0.95(0.69,1.32)$ & 0.787 & $0.98(0.70,1.36)$ & 0.915 \\
\hline Higher Class & $0.92(0.68,1.23)$ & 0.608 & $0.95(0.71,1.28)$ & 0.759 \\
\hline $\begin{array}{l}\text { Has No Mobile } \\
\text { Phone }\end{array}$ & Ref & & & \\
\hline Has Mobile Phone & $1.99(1.21,3.28)$ & 0.006 & $2.05(1.26,3.32)$ & 0.003 \\
\hline Has Radio & $0.85(0.68,1.07)$ & 0.182 & $0.81(0.63,1.05)$ & 0.189 \\
\hline
\end{tabular}

KEY: $\mathrm{COR}=$ Crude Odds Ratio; $\mathrm{AOR}=$ Adjusted Odds Ratios; $\mathrm{CI}=$ Confidence Interval.

\section{Discussion of Findings}

This study was investigating individual factors and their association with agreeing to early childbearing among school going adolescent girls in selected rural areas of Zambia.
Despite the study having a large sample size, certain factors which are practically key in issues to deal with early childbearing in rural areas such as cultural and socioeconomic factors as measured at baseline, there was no 
evidence of an association with early childbearing in this study. This can be explained by the fact that this was a randomized trial, hence at baseline, it is unlikely for us to observe any differences if randomisation worked. However, after a further investigation of each individual variable under socio-economic factors, owning a mobile phone by an adolescent girl showed significant association with the proxy to early childbearing.

Ownership and access to mobile devices in Zambia, especially the mobile phone, has changed significantly since 2006. Rural households have shown an increase in ownership from $8.8 \%$ in 2006 to $32 \%$ in 2010 [10]. About $51 \%$ of people aged 10 years are active users of mobile phones and $71 \%$ of individuals that own smart phones use the device to access social media applications such as Facebook and whatsapp [11].

Cell phone usage promotes easy communication among peers and their partners and also gives them easy access to the internet which they use without regulation, to surf explicit content motivating early sex [12]. Literature has shown that engaging in various forms of social media is routine activities that benefit children and adolescents by enhancing communication, social connection, and even technical skills [13].

Social media sites such as facebook and whatsapp offer multiple daily opportunities for connecting with friends, classmates, and people with shared interests. During the last 5 years, the number of adolescents using such sites increased dramatically. Twenty-two percent of teenagers log on to their favourite social media site more than 10 times a day, and more than half of adolescents log on to a social media site more than once a day [14]. Seventy five percent of teenagers now own cell phones, and $25 \%$ use them for social media, $54 \%$ use them for texting, and $24 \%$ use them for instant messaging [9].

A large part of this generation's social and emotional development is occurring while on the Internet and on cell phones. Some of the adolescents use mobile phones for sexting. Sexting can be defined as "sending, receiving, or forwarding sexually explicit messages, photographs, or images via cell phone, computer, or other digital devices." Many of these images become distributed rapidly via cell phones or the internet [12]. This phenomenon does occur among the teen population; a recent survey revealed that $20 \%$ of teens have sent or posted nude or semi-nude photographs or videos of themselves [15], these predisposes adolescents into engaging in childbearing activities.

The findings from this study revealed that most of the respondents who agreed to early childbearing 227 (69.6\%) were aged 10 to 15 years as shown in table two and it is in this age group in which if a girl happens to have a baby is referred to as early child birth according to the constitution of Zambia, in addition it was revealed that one year increase in age of adolescents increases the likelihood of early childbearing by $30 \%$, the increase can be as high as $67 \%$ or as low as $1 \%$ (see Table 2). This is in line with several literatures revealed in which the proportion of women who become pregnant before age of 15 varies enormously even within regions and countries. For example, the rate in Rwanda is $0.3 \%$ compared to $12.2 \%$ in Mozambique [4]. A similar study that was done by ZDHS, 2007 which revealed a notable increase in early childbearing from $4.9 \%$ to $58.9 \%$ from adolescent girls aged 10 to 15 years in selected rural districts of Zambia. Therefore it is of great importance that the government and key stakeholders provide health education messages on the consequences of early childbearing to these adolescent girls which may include fistulas, post-partum haemorrhage, abortions and in some instances death.

A critical barrier facing adolescents is a lack of knowledge. Girls and boys go through puberty with little understanding of the changes taking place in their bodies and even less understanding of contraception [16]. Results from this study revealed that the majority of adolescents 3404 (74\%) had no knowledge regarding adolescent sexual and reproductive health services. This is in line with a study by Palamuleni [17] who pointed out that until recently knowledge and access to reproductive health services in Southern Africa has concentrated its effort on older women, or women who are already mothers. Another study by Marteleto [17] revealed that many adolescents believe that the uses of contraceptives make them sterile, and that plastic wrap make an effective condom. Some teenagers believe that they can't get pregnant in the first time of sexual intercourse, if they are having their period, if the male withdraws in time, and they are having sex in a standing position. It is from this vain that adolescent girls need to be abreast with correct information regarding sexual and reproductive health both in school and out of school in order to prevent early childbearing.

Finally, we recommend that it is of great importance that there some restrictions in the use of mobile phones by adolescents younger than 16 years.

\section{Limitations}

This study was using secondary data that was collected at baseline in the RISE study. The data that was being analysed had limited information on variables such as peer pressure and access to reproductive health information by adolescents girls in selected rural districts of Zambia, the outcome variable early childbearing was a proxy variable which was quite subjective in the way the respondents were giving their responses.

\section{Conclusion}

In conclusion, use of a mobile phone by an adolescent girl and one year increase in age of an adolescent girl were associated with agreeing to early childbearing. A notable number of adolescent girls who agreed to engage into early childbearing practices in exchange for a phone were aged 1015 years in the CISMAC RISE trial at baseline. It was noted that the percentage of agreeing to early childbearing increased steadily as an adolescent girl increases in age, and 
lastly but not the least with regards to knowledge, most of the girls had little or no knowledge regarding Sexual and Reproductive Health information particularly family planning use.

\section{Authors Contributions}

All authors contributed extensively to the work presented in this paper. All authors read and approved the final manuscript.

\section{Ethics Approval and Consent to Participate}

This study was approved by biomedical research ethics committee UNZA-BREC, on the 25th of September, 2017 with reference number 025-06-17.

\section{Human and Animal Rights}

No animals/humans were used for studies that are the basis of this research.

\section{Consent for Publication}

Not applicable, however, consent was obtained from the investigators of the original study, further, the original study sought consent and ascent from study participants. The RISE study team approved for this study to be published.

\section{Competing Interests}

The authors declare no conflict of interest, financial or otherwise.

\section{Availability of Data and Material}

The data used for this study can be obtained by requesting the CISMAC RISE project.

\section{Funding}

The Research Initiative to Support the Empowerment of girls (RISE) trial is funded by the Research Council of Norway through its Centres of Excellence Scheme to the Centre of Intervention Science in Maternal and Child Health (CISMAC; project number 223269) and the Global Health and Vaccination Programme (GLOBVAC; project number 248121).

\section{Acknowledgements}

I would like to thank CISMAC RISE Project for allowing me to have access to their baseline data and investigate some of the factors that may be associated with early childbearing among adolescent girls of selected rural districts in Zambia.

Patrick Musonda would like to acknowledge that some of his time is supported by the Research Council of Norway through its Centres of Excellence Scheme to the Centre of Intervention Science in Maternal and Child Health (CISMAC; project number 223269) and through the Global Health and Vaccination Programme (GLOBVAC; project number 248121). In addition, some of his time is also supported by the welcome trust; the Department for International Development; the Alliance for Accelerating Excellence in Science in Africa (DELTAS). Grant Number: [107754/Z/15/Z]. None of these organisations have contributed in any way in writing of this manuscript; any error arising in this publication is thoroughly the authors' problem.

\section{References}

[1] Mkhwanazi $\mathrm{N}$ et al. Developing and expanding our ideas about teenage desire and fertility. Agenda 2011; 25 (3): 2-8.

[2] Sandøy, I. F. et al. Effectiveness of a girls' empowerment programme on early childbearingmarriage and school dropout among adolescent girls in rural Zambia: study protocol for the cluster randomised trial. Trial 2016; 17 (1): 588.

[3] Kirby D et al. Antecedents of adolescent initiation of sex, contraceptive use, and pregnancy. American Journal of Health Behavior. 2002; 26 (6): 473-85.

[4] World Health Organization. Child marriages country profile elinquency. J Sch violence 2007; 6 (3): 89-112.

[5] Amoran OE. A comparative analysis of predictors of teenage pregnancy and its prevention in a rural town in Western Nigeria. International journal for equity in health 2012; 11 (1): $1-7$.

[6] Central Statistical Office (CSO) [Zambia], Ministry of Health (MOH) [Zambia], ICF International. Zambia Demographic and Health Survey 2013-14. Rockville, Maryland, USA: Central Statistical Office, Ministry of Health, and ICF International; 2014.

[7] Lloyd CB, Mensch BS et al. Marriage and childbirth as factors in dropping out from school: An analysis of DHS data from sub-Saharan Africa. Popul Stud (Camb) 2008; 62 (1): 1-13.

[8] Walker, $\mathbf{J}$ et al. Early Marriage in Africa Trends, Harmful Effects and Interventions Zones of early marriages in Africa. African Journal of Reproductive Health. 2012; 16 (2): 231240 .

[9] Gibbons et al. "Understanding attitudes and predicting social behavior. Englewood Cliffs, NJ: Prentice Hall. 1998; 12 (8) 61-64

[10] Hinduja S, Patchin, J et al. Offline consequences of online victimization. school violence and deliquency 2010; 6 (3): 89112 .

[11] Kemp, N. et al. Mobile technology and literacy: Effects across cultures, abilities and the lifespan. Journal of Adolescent \& Adult Literacy. 2011; 27 (1): 1-3.

[12] Carbonell, X., Chamarro, A., Griffiths, M., Oberst, U., Cladellas, R., \& Talarn, A. Problematic Internet and cell phone use in Spanish teenagers and young students. Anales de Psicología. 2012; 28 (3): 789-796. 
[13] Mitchell, K. J., Becker-Blease, K. A., \& Finkelhor, D et al. Inventory of problematic Internet experiences encountered in clinical practice. Professional Psychology: Research and Practice. 2005; 36 (5):498-309.

[14] Williams, K., \& Guerra, N. G et al. Prevalence and predictors of Internet bullying. Journal of Adolescent Health 2007; 41 (6): 14-21.

[15] Palermo T, Peterman A et al. Are Female Orphans at Risk for Early Marriage, Early Sexual Debut, and Teen Pregnancy? Evidence from Sub-Saharan Africa. Studies in Family Planning. 2009; 40 (2): 101-12.
[16] Dixon Muellen. R et al. How young is too young? studies in family planning. 2008; 39 (4): 247-62.

[17] Palamuleni M, Adebowale A et al. Patterns of premarital childbearing among unmarried female youths in sub-Saharan Africa: Evidence from demographic health survey. Scientific Research and Essays. 2014; 9 (10): 421-30.

[18] Marteleto, L., Lam, D., \&\& Ranchod, V et al. Sexual behaviour, pregnancy and schooling among young people in urban South Africa. Studies in family planning. 2008; 39 (4): 351-368. 